\title{
RESISTENCIA AL IÓN COBRE DE Xanthomonas arboricola pv. juglandis EN NOCEDALES DE LA REGIÓN DEL BIOBÍO
}

\section{RESISTANCE OF Xanthomonas arboricola pv. juglandis TO ION COPPER IN WALNUT ORCHARDS IN THE BIOBÍO REGION}

\author{
Ernesto Moya-Elizondo ${ }^{1 *}$, Pablo Auil ${ }^{1}$, Pía Oyarzúa ${ }^{1}$, y Macarena Gerding G. ${ }^{1}$ \\ ${ }^{1}$ Facultad de Agronomía, Departamento de Producción Vegetal, Universidad de Concepción, Avda. \\ Vicente Méndez 595, Chillán, Chile. \\ * Autor para correspondencia E-mail: emoya@udec.cl
}

\section{RESUMEN}

La enfermedad conocida como peste negra, causada por la bacteria Xanthomonas arboricola pv. juglandis (Xaj) afecta severamente al cultivo del nogal en la Región del Biobío en Chile. El control está basado principalmente en aplicaciones excesivas de bactericidas cúpricos (12 a 14 aplicaciones por estación de crecimiento), lo cual puede generar resistencia por parte de la bacteria. Esta investigación evaluó, bajo condiciones in vitro, la sensibilidad bacteriana a distintas concentraciones del ion cobre $\left(\mathrm{Cu}^{+2}\right)$ en aislados bacterianos de Xaj provenientes de cuatro huertos de la Región del Biobío. Se encontró niveles de resistencia al cobre por parte de las bacterias que fue superior a los niveles reportados hasta la fecha en Chile, siendo esta sensibilidad indiferente del bactericida cúprico utilizado (sulfato de cobre, hidróxido de cobre y óxido de cobre I), y presente en aislados de Xaj obtenidos desde tres de los cuatro predios evaluados.

Palabras clave: Peste negra, resistencia a cobre, nogal.

\section{SUMMARY}

The walnut blight disease, caused by the bacterium Xanthomonas arboricola pv. juglandis (Xaj) severely affects walnut production in the Biobío Region in Chile. The disease control is based on the excessive use of cupric bactericides (12 to 14 spray applications during the growing season), which can generate resistance by the bacteria. This research evaluated the in vitro bacterial resistance of bacterial strains of $X a j$ to ion copper $\left(\mathrm{Cu}^{+2}\right)$ at different concentrations. The strains were obtained from four orchards located in the Biobío Region. Levels of copper resistance were higher than those previously reported in Chile, irrespective of the copper bactericides used (copper sulfate pentahydrate, copper hydroxide, and copper (I) oxide). Sensible isolates of Xaj were observed in three of the four walnut orchards sampled. 


\section{INTRODUCCIÓN}

En Chile existen alrededor de 17 mil hectáreas plantadas con nogal (Juglans regia L.), , de las cuales aproximadamente 800 ha están en la Región del Biobío, donde predominan los cultivares Chandler y Serr (Larrañaga y Osores, 2012). En cuanto a la producción del cultivo, la mayor limitante que presenta es la enfermedad denominada peste negra del nogal, que es causada por la bacteria Xanthomonas arboricola pv. juglandis (Pierce) (Vauterin et al., 1995; Temperini et al. 2014) (Xaj), que se encuentra ampliamente distribuida en todos los países en que se cultiva esta especie, especialmente en aquellas zonas que presentan primaveras húmedas y templadas (Esterio et al., 2006).

En Chile la incidencia de peste negra aumenta desde el norte al sur, debido a la mayor frecuencia de precipitaciones primaverales, lo cual repercute en la presión de la enfermedad. La severidad del ataque ha sido relacionada con la presencia de agua libre sobre los tejidos del huésped (Lamichhanne, 2014) asociado a la frecuencia y la cantidad de lluvia en primavera, e influido por la fecha de brotación del cultivar, el potencial del inóculo y la historia de la enfermedad en el huerto (Ninot et al. 2002).

Todos los tejidos de nogal son susceptibles a la infección; la infección ocurre en hojas, brotes verdes, amentos, flores femeninas y frutos (Lamichhanne, 2014; Lindow et al., 2014). Sin embargo, el principal daño es en el fruto, ya que infecciones tempranas en su desarrollo generan la caída de los frutos (Gardan et al., 1993) y en etapas más tardías, la bacteria causa una mancha acuosa sobre el pericarpio que disminuye su calidad e impide su comercialización (Ninot et al., 2002).

El control de esta enfermedad se basa principalmente en el uso de bactericidas cúpricos (Ninot et al., 2002; Lindow et al., 2014), que funcionan recubriendo la superficie de la hoja con partículas microscópicas de cobre que liberan iones, que dañan las membranas y proteínas de las bacterias, y puede retardar o inhibir su multiplicación (López y Castaño, 2011; Lamichhane y Varvaro, 2014).

Las principales formas genéricas de sales de cobre utilizadas para el control de peste negra son: oxicloruro de cobre, sulfato de cobre, hidróxido de cobre, óxido de cobre (I) (también denominado como óxido cuproso), caldo bordelés (combinación de sulfato cúprico y cal hidratada), y recientemente se está comenzando a explorar con nuevas formulaciones que acomplejan el cobre con moléculas orgánicas. Sin embargo, productos a base de sales de cobre altamente solubles pueden causar problemas de fitotoxicidad. Además, estos productos favorecen la acumulación de $\mathrm{Cu}^{+2}$ en el suelo desequilibrando el contenido de polifenoles en los tejidos del nogal, que se asocia a las defensas naturales de la planta frente a la bacteria (Ninot et al., 2002) y puede favorecer la ocurrencia de cepas tolerantes al cobre (López y Castaño, 2011; Lamichhane y Varvaro, 2014).

Se han aislado cepas bacterianas con resistencia a cobre desde nocedales donde se ha hecho un uso intensivo de bactericidas cúpricos (Lee et al., 1993; Gardan et al., 1993; Basim et al., 2005; Esterio et al., 2006; Behlau et al., 2012). En Chile, Esterio et al. (2006) evaluando la resistencia al ion cobre en 131 cepas de Xaj obtenidas desde tres predios ubicados en Rinconada de Maipú, Rancagua, y Quinta de Tilcoco, y sometidos a diferentes presiones de selección por cobre $(0,5-6$, y 12 - 15 aplicaciones / temporada, respectivamente), obtuvieron que un $29,8 \%$ de las cepas analizadas (39 cepas) mostraron crecimiento in vitro a una concentración por sobre $32 \mu \mathrm{g} \mathrm{Cu}^{+2} \mathrm{~mL}^{-1}$ que es la concentración inhibitoria mínima para resistencia bacteriana a este metal (Gardan et al., 1993). Este resultado constituye la primera referencia descrita de resistencia a cobre en bacterias fitopatógenas en Chile.

La producción de nocedales en la Región del Biobío es severamente afectada por la peste negra del nogal, y para el control se ha recurrido al uso de varias aplicaciones de productos cúpricos durante la temporada de producción (12 a 14 aplicaciones) lo cual podría estar favoreciendo la selección y aparición de razas resistentes de Xaj. Esto también podría acelerarse, si se considera que gran parte de las plantaciones que se establecen en la Región del Biobío provienen de viveros de la zona central, que están localizados en el área donde se detectó resistencia a cobre descrita por Esterio et al., (2006). Por lo anterior, es importante monitorear la resistencia a cobre en poblaciones de esta bacteria que estén presentes en la Región del Biobío.

Basado en estos antecedentes, se evaluó la resistencia al ion cobre en aislados de X. arboricola pv. juglandis obtenidos desde cuatro nocedales comerciales de la Región del Biobío.

\section{MATERIALES Y MÉTODOS}

\section{Aislamiento de poblaciones bacterianas}

Muestreo de huertos de nogal. Se recolectaron aleatoriamente frutos inmaduros de nogal sintomáticos a la enfermedad desde cuatro huertos comerciales ubicados en la región del Biobío. Un huerto localizado en Chillán (36 $35^{\prime} 54^{\prime \prime}$ S; $\left.72^{\circ} 04^{\prime} 43^{\prime \prime} \mathrm{O}\right)$ fue muestreado por no haber recibido aplicaciones regulares de productos a base de cobre en los tres últimos años, mientras que los tres huertos restantes, localizados en Mulchén 


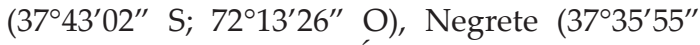
S; $72^{\circ} 28^{\prime} 07^{\prime \prime}$ O) y Los Ángeles, sector Huaqui

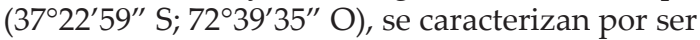
asperjados regularmente con productos en base a cobre y haber presentado una incidencia relativamente alta de peste negra. Todos los huertos fueron muestreados en febrero de 2013.

\section{Origen de los aislados}

A partir de 20 frutos colectados desde cada huerto muestreado, se cortaron pequeños trozos del tejido pericárpico que presentaron sintomatología característica de la enfermedad, hasta lograr un gramo de tejido desde cada fruto individual, el cual se molió en un mortero y se agregó a $9 \mathrm{~mL}$ de agua destilada estéril. La suspensión resultante de la molienda de la muestra de cada fruto fue diluida tres veces en agua destilada estéril (ADE) y la presencia de X. arboricola pv. juglandis (Xaj) fue verificada tomando $100 \mu \mathrm{L}$ desde la dilución $10^{-4}$, que fue esparcida homogéneamente sobre placas individuales con medio agar extracto de levadura-dextrosa-carbonato de calcio (YDC). Las placas fueron incubadas a $25^{\circ} \mathrm{C}$ por $48 \mathrm{~h}$. De acuerdo a Moragrega (2012), se consideró como $X a j$ a aquellas colonias bacterianas que se observaron de color amarillo intenso y que con el tiempo se tornaron de un color anaranjado sobre el medio.

A partir de cada muestra obtenida desde cada uno de los 20 frutos obtenidos de cada huerto en estudio, se agregó $5 \mathrm{~mL}$ de solución salina (0,89\% $\mathrm{p} / \mathrm{v}$ ) sobre el medio sólido YDC con las colonias bacterianas, se raspó la superficie del medio para suspender las bacterias y se extrajo una alícuota de $5 \mu \mathrm{L}$ de las poblaciones bacterianas aisladas, las que fueron inoculadas en $1 \mathrm{~mL}$ de medio líquido (LB) a $25^{\circ} \mathrm{C}$ por 48 horas en agitación constante. A partir de cada tubo, utilizando un asa bacteriológica, se procedió a la siembra de 1,0 $\mu \mathrm{L}$ en medio YDC. Las placas con YDC fueron incubadas por $48 \mathrm{~h}$ a $25^{\circ} \mathrm{C}$, y posteriormente de cada placa representando la población bacteriana infectando un fruto se aisló una colonia que presentaba las características de Xaj hasta completar 20 aislados por huerto

Determinación de resistencia al ion cobre en aislados de Xanthomonas arboricola pv. juglandis.

i) Determinación de resistencia a sulfato de cobre pentahidratado $\left(\mathrm{CuSO}_{4} \cdot 5 \mathrm{H}_{2} \mathrm{O}\right)$ en medio agar Luria Broth (LB).

La sensibilidad de la bacteria al cobre fue determinada mediante pruebas in vitro, utilizando sulfato de cobre pentahidratado con pureza del $99 \%\left(\mathrm{PM}=249,68 \mathrm{~g} \mathrm{~mol}^{-1}\right)$, siguiendo una metodología modificada de aquella descrita por Esterio et al. (2006). Se determinó clasificar como resistente a aquellos aislados que fueran capaces de crecer a una concentración $\geq 32 \mu g \mathrm{~mL}^{-1} \mathrm{de} \mathrm{Cu}^{+2}$, según lo propuesto por Gardan et al. (1993). Los 20 aislados individuales de cada huerto fueron sembrados con una pipeta multicanal en líneas de 5 individuos, sobre medio agar LB con concentraciones crecientes de cobre: 0, 80, 120 y $160 \mu \mathrm{g}$ $\mathrm{mL}^{-1} \mathrm{de} \mathrm{Cu}^{+2}$. Los aislados individuales que se colocaron sobre los medios de cultivo se obtuvieron tomando una alícuota de $2,5 \mu \mathrm{L}$ del crecimiento bacteriano que se obtuvo al crecer previamente cada aislado de forma individual en pocillos con $200 \mu \mathrm{L}$ de medio caldo LB en una placa multipocillo de 96 celdas, la cual fue incubada previamente por $48 \mathrm{~h}$ a $25^{\circ} \mathrm{C}$. El crecimiento de las bacterias en el caldo LB puro de la placa multipocillo se determinó previo a su uso a través de lecturas de densidad óptica a $600 \mathrm{~nm}$ en un lector de microplacas, considerándose un valor $\geq 0,1$ como crecimiento positivo. Para determinar las concentraciones de cobre se consideró que $0,16 \mathrm{mM}$ de $\mathrm{CuSO}_{4} \times 5 \mathrm{H}_{2} \mathrm{O}$ equivalen a $10 \mu \mathrm{g} \mathrm{mL}-1$ de $\mathrm{Cu}^{+2}$ (Menkissoglu y Lindow, 1991). Finalmente, por cada concentración se consideró dos repeticiones para cada aislado bacteriano en evaluación. Las placas fueron incubadas a $25^{\circ} \mathrm{C}$ y evaluadas en su crecimiento bacteriano a las 48 y $120 \mathrm{~h}$ posteriores a la inoculación, para determinar la susceptibilidad o resistencia de los aislados de acuerdo a su crecimiento en las distintas concentraciones de cobre evaluadas. Se criopreservaron 10 aislados por predio, los cuales se utilizaron en todos los ensayos que se describen a continuación.

\section{ii) Determinación de resistencia de aislados bacterianos a $\mathrm{CuSO}_{4} \cdot 5 \mathrm{H}_{2} \mathrm{O}$ en caldo $\mathrm{LB}$ (Medio líquido)}

Los 10 aislados seleccionados por predio se pusieron a crecer en pocillos individuales en una placa multipocillo de 96 celdas, agregando $5 \mu \mathrm{L}$ de cada aislado en $200 \mu \mathrm{L}$ de medio caldo LB, el cual se incubó por $48 \mathrm{~h}$ a $25^{\circ} \mathrm{C}$. El crecimiento bacteriano se determinó como positivo como descrito anteriormente mediante espectrofotometría. Las bacterias crecidas fueron traspasadas con una pipeta multicanal a otra placa multipocillo, tomando $50 \mu \mathrm{L}$ de cada cultivo bacteriano individual, el cual fue adicionados sobre un volumen de $150 \mu \mathrm{L}$ de medio LB enmendado con sulfato de cobre pentahidratado para conseguir concentraciones de $0,32,80$ y $120 \mu \mathrm{g} \mathrm{mL}^{-1}$ de $\mathrm{Cu}^{+2}$ e incubados nuevamente por $48 \mathrm{~h}$ a $25^{\circ} \mathrm{C}$. El control sin sulfato de cobre pentahidratado $\left(0 \mu \mathrm{g} \mathrm{mL} \mathrm{mL}^{-1}\right.$ de $\mathrm{Cu}^{+2}$ ) consistió en $150 \mu \mathrm{L}$ de caldo LB puro. Después de esta incubación, los aislados de cada predio, cultivados a distintas concentraciones de cobre fueron sembrados en líneas de 10 alícuotas 
individuales de $2,5 \mu \mathrm{L}$ por aislado en una placa de Petri conteniendo medio agar LB, siendo replicado el crecimiento bacteriano en tres placas. Las placas fueron incubadas a $25^{\circ} \mathrm{C}$ y se evaluó el crecimiento bacteriano a las 48 y $120 \mathrm{~h}$ posteriores a la inoculación, para determinar la incidencia de aislados susceptibles o resistentes en las distintas concentraciones de cobre evaluadas de cada predio en evaluación.

\section{iii) Determinación de resistencia de aislados bacterianos a distintas sales de cobre}

Para evaluar la efectividad de control de distintos productos comerciales en base a sales de cobre, se utilizaron los 10 aislados antes descritos, siguiendo la metodología descrita en el punto ii), pero agregando los $50 \mu \mathrm{L}$ del crecimiento bacteriano en un volumen de $150 \mu \mathrm{L}$ de medio LB enmendado con óxido de cobre (I) (Nordox 75 WP®), hidróxido de cobre (Kocide ${ }^{\circledR}$ 2000), sulfato de cobre pentahidratado $\left(\mathrm{CuSO}_{4} \cdot 5 \mathrm{H}_{2} \mathrm{O}\right)$ y medio LB puro, el cual se consideró un control. Agregado el cultivo bacteriano, la concentración final equivalente de óxido de cobre fue de $1,5 \mathrm{~g}$ de $\mathrm{Cu}^{+2} \mathrm{~L}^{-1}$ ( $2 \mathrm{~g} \mathrm{~L}^{-1}$ del producto comercial), de hidróxido de cobre fue de $0,875 \mathrm{~g}_{\text {de }} \mathrm{Cu}^{+2} \mathrm{~L}^{-1}(2,5 \mathrm{~g}$ $\mathrm{L}^{-1}$ del producto comercial), de $\mathrm{CuSO}_{4} \cdot 5 \mathrm{H}_{2} \mathrm{O}$ fue de $1,18 \mathrm{~g}$ de $\mathrm{Cu}^{+2} \mathrm{~L}^{-1}\left(4,6 \mathrm{~g} \mathrm{~L}^{-1}\right.$ del producto estándar). Los aislados en evaluación colocados en los tratamientos descritos anteriormente fueron incubados por $48 \mathrm{~h}$ a $25^{\circ} \mathrm{C}$, para ser sembrados en alícuotas individuales de $2,5 \mu \mathrm{L}$ de cada tratamiento sobre una placa de Petri conteniendo medio agar LB, que fue replicado tres veces. Las placas fueron incubadas a $25^{\circ} \mathrm{C}$ y evaluadas en su crecimiento bacteriano a las $48 \mathrm{~h}$ posteriores a la inoculación, para determinar la incidencia de aislados susceptibles o resistentes en las distintas formulaciones y concentraciones de cobre evaluadas. Adicionalmente, se evaluó el nivel de eficacia de control de las distintas sales a igual concentración de ion cobre, siguiendo la misma metodología descrita anteriormente, pero usando una concentración estandarizada de $1,5 \mathrm{~g}$ de $\mathrm{Cu}^{+2}$ $\mathrm{L}^{-1}$ para las tres sales de cobre en evaluación.

\section{Test de patogenicidad de cepas de Xaj en frutos inmaduros de nogal}

Se recolectaron frutos inmaduros de nogal aparentemente sanos que fueron desinfectados en hipoclorito de sodio al 5\% (i.a.) por $5 \mathrm{~min}$, y lavados tres veces con agua destilada estéril previo a su utilización. El test de patogenicidad se realizó siguiendo la metodología descrita por Moragrega (2001). Los 10 aislados bacterianos seleccionados por predio fueron crecidos en agitación en caldo LB por $48 \mathrm{~h}$ a $25^{\circ} \mathrm{C}$ para permitir la multiplicación bacteriana. Con una aguja se hicieron 3 inoculaciones de $10 \mu \mathrm{L}$ cada una alrededor de la zona ecuatorial del fruto: dos inoculaciones de la suspensión bacteriana y otra con agua destilada estéril a nivel de mesocarpo (justo al final del tejido verde, limitando con el tejido blanco) y se marcaron para poder reconocer los puntos inoculados. Se utilizaron tres frutos por aislado bacteriano. Los frutos inoculados se pusieron de forma individual en los alveolos de una bandeja de huevos que en su base tenían un trozo de papel absorbente humedecido con agua destilada estéril, y fueron colocadas dentro de una bolsa plástica que fue sellada para generar una cámara húmeda. Después de 15 días los frutos fueron cortados a nivel ecuatorial para analizar el nivel de severidad de la enfermedad presente en el interior de estos, mediante una escala donde: $0=$ no hubo infección; $1=$ necrosis ubicada en el punto de inoculación; 2 = necrosis extendida desde el punto de inoculación por todo el tejido verde; 3 = necrosis extendida a través del mesocarpo y alcanzando el endocarpo; y 4 = necrosis afectando la semilla (Moragrega, 2001).

\section{Análisis estadístico}

Los resultados obtenidos en los ensayos de resistencia a cobre se analizaron con estadística descriptiva.

\section{RESULTADOS Y DISCUSIÓN}

Las bacterias aisladas desde frutos infectados por peste negra se observaron como colonias de color amarillo intenso, que con el tiempo se fueron tornando de un color anaranjado, siendo esta característica más acentuada en los aislados obtenidos desde el huerto de Chillán, mientras que los aislados obtenidos de los huertos de Los Ángeles, Negrete, y Mulchén, tuvieron un color amarillo menos intenso. La prueba de patogenicidad mostró que los aislados bacterianos de Chillán, Negrete y Mulchén fueron capaces de infectar la semilla de los frutos. Los aislados de Chillán fueron patogénicamente más severos, mientras los 10 aislados provenientes de Los Ángeles no generaron síntomas visibles en los frutos después de 15 días desde la inoculación.

Los aislados de Xaj obtenidos de nocedales de la región del Biobío crecieron en medios que contenían cobre, después de transcurridas 48 h de incubación de las bacterias en medio agar LB. Los aislados de Xaj provenientes de frutos enfermos de los nocedales ubicados en Chillán, Los Ángeles y Negrete crecieron en todas las concentraciones de cobre que fueron testeadas $(0,80,120$ y $160 \mu \mathrm{g} \mathrm{mL}^{-1} \mathrm{de} \mathrm{Cu}^{+2}$ ), mientras que los aislados de Mulchén fueron susceptibles y sólo crecieron en el control (Fig. 1A). Los aislados de Chillán 


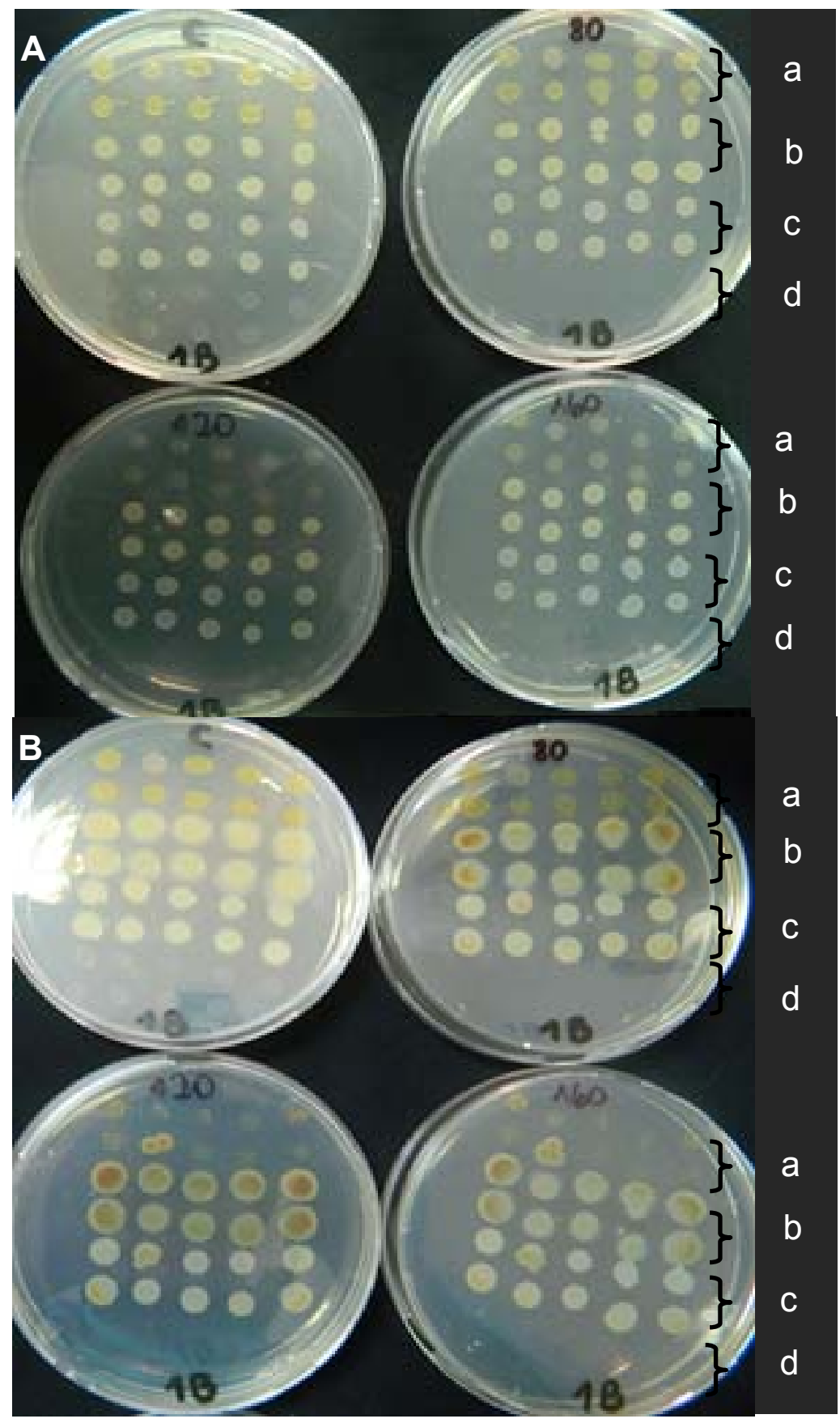

Fig. 1. Grupos de 10 aislados de bacterias Xanthomonas arboricola pv. juglandis obtenidas desde huertos de nogal ubicados en cuatro localidades de la Región del Biobío (a: Chillán; b: Negrete; c: Los Ángeles; d: Mulchén) y sembradas en diferentes concentraciones de $\mathrm{Cu}^{+2}(0$, 80, 120 y $160 \mu \mathrm{g} \mathrm{mL}^{-1}$ ) después de 48 (A) y 120 horas de incubación (B).

Fig. 1. Groups of 10 bacterial isolates of Xanthomonas arboricola pv. juglandis obtained from walnut orchards in four different locations in the Biobío Region (a: Chillán; b: Negrete; c: Los Ángeles; d: Mulchén). They were sown at different concentrations of $\mathrm{Cu}^{+2}(0,80,120$, and 160 $\mu \mathrm{g} \mathrm{mL} \mathrm{L}^{-1}$ ) after 48 (A) and 120 hours of incubation (B). 
mostraron una menor expresión del pigmento amarillo característico del género Xanthomonas en las tres concentraciones de cobre evaluadas con respecto al control, acentuándose notoriamente a 120 y $160 \mu \mathrm{g} \mathrm{mL}^{-1}$ de $\mathrm{Cu}^{+2}$, a diferencia de lo observado en los aislados de Los Ángeles y Negrete, que se mostraron sin variación en color en todas la concentraciones de cobre evaluadas. Existen escasos reportes acerca de la influencia de la concentración de sales en la producción de pigmentos bacterianos, y los factores que influyen en su producción son variados (Gómez-Marín et al., 2009). La falta de patogenicidad y cambios de coloración pueden ser explicadas porque las bacterias ante situaciones de presión selectiva cómo es la aplicación de cobre sufren un costo metabólico en el cual el microorganismo pierde ciertas características genéticas al adquirir una nueva capacidad genética que le entrega alguna habilidad adaptativa de supervivencia o reproducción (Leach et al., 2001). Posiblemente, el costo metabólico de los aislados de Xaj obtenidos en el huerto de Chillán estuvo asociado a la disminución en la síntesis de pigmento en pos de tratar de sobrevivir y desintoxicarse ante las elevadas concentraciones de iones $\mathrm{Cu}^{+2}$ a que fueron sometidas, ya que sus controles mostraron una pigmentación normal. Por su parte, la no variación en el color que presentaron los aislados de Los Ángeles y Negrete, sugiere que estarían mejor adaptados a los excesos de cobre, ya que han estado sometidas a una mayor presión de selección en los predios desde donde se aislaron. Por otra parte, el color obtenido en el control entre los aislados de los diferentes predios no fue homogéneo, esta heterogeneidad sugiere una variabilidad genética en cepas de Xaj provenientes de diferentes localidades del valle central de Chile, donde se determinó que bacterias expuestas con mayor frecuencia a productos cúpricos modifican su patrón genotípico en respuesta a esta condición de estrés (Pérez, 2005).

Transcurridas $120 \mathrm{~h}$ de la incubación bacteriana (Fig. 1B) en las placas se observó una reducción del área de crecimiento alrededor del punto de inoculación de los aislados de Chillán en las concentraciones de 120 y $160 \mu \mathrm{g} \mathrm{mL}^{-1} \mathrm{de} \mathrm{Cu}^{+2}$. Los aislados de Los Ángeles y Negrete no vieron reducida su área de crecimiento, sin embargo adquirieron una tonalidad color ocre, lo que sugiere algún tipo de acumulación interna de cobre por parte de las bacterias. Este cambio de color ha sido reportado en cepas de X. euvesicatoria (Xe) (X. axonopodis [syn. campestris] pv. vesicatoria (Jones et al., 2004), donde se estudió el nivel de resistencia in vitro a $\mathrm{Cu}^{+2}$, y se determinó que la cepa más tolerante a cobre, presentó una mayor intensidad del color y la capacidad de acumular cobre en la periferia celular cuando entraba en contacto con este elemento (Ramos y Rosato, 1996). Es probable que los aislados de Xaj de Los Ángeles y Negrete podrían utilizar este mecanismo para tolerar elevadas concentraciones de $\mathrm{Cu}^{+2}$; sin embargo, se requiere realizar estudios de microscopía electrónica espectroscópica para validar esta aseveración.

Cepas fitobacterianas resistentes a cobre han sido sólo descritas en los géneros Pseudomonas y Xanthomonas (Murillo y Rodriguez-Palenzuela, 1996) y la resistencia a cobre en $X a j$ ha sido poco estudiada en comparación a otras bacterias fitopatógenas. Los genes de resistencia a cobre, denominados genes cop, en el género Xanthomonas comúnmente se encuentran en genes localizados en plásmidos (Murillo y Rodriguez-Palenzuela, 1996), sin embargo, estos genes también pueden localizarse en el cromosoma bacteriano de las cepas resistentes de Xaj (Lee et al., 1994). En Chile, un reciente estudio detectó la presencia de los genes $\operatorname{cop} A, \operatorname{cop} B, \operatorname{cop} D, \operatorname{cop} G, \operatorname{cus} C, \operatorname{cus} F, C u t A, y$ $\mathrm{CutC}$ asociados con mecanismos de resistencia a cobre en un estudio del genoma de cuatro aislados de Xaj (Higueras et al., 2015). No obstante lo anterior, no existen reportes del origen de dichos aislados y la implicancia de su presencia en la expresión de la enfermedad.

Los genes y sistema de resistencia en Xaj presentes en las poblaciones resistentes encontradas en los huertos muestreados de la región del Biobío, requerirá de un estudio molecular para dilucidarlo. Especialmente considerando que los niveles de resistencia a cobre obtenidos en nuestro ensayo muestran un incremento del $150 \%$ en comparación con la máxima concentración de cobre in vitro que pudieron tolerar dos de las 131 cepas bacterianas aisladas por Esterio et al. (2006) en su investigación, las cuales crecieron hasta una concentración máxima de $64 \mu \mathrm{g} \mathrm{mL}^{-1} \mathrm{de} \mathrm{Cu}^{+2}$. $\mathrm{La}$ aparición de nuevas cepas o el aumento en los niveles de resistencia de las poblaciones de Xaj presentes en la Región de Biobío supone un problema productivo, ya que la resistencia a cobre implica una menor respuesta a las aplicaciones de este bactericida, y un riesgo de expansión de estos niveles de resistencia mediante el traspaso de plásmidos conjugativos entre cepas bacterianas de $\mathrm{X} a j$, como fue demostrado tempranamente por Gardan et al. (1993), por lo que es importante determinar donde subyacen los genes de resistencia que prevalecen en las poblaciones de Xaj presentes en huertos de la región del Biobío.

Al evaluar la susceptibilidad de los aislados bacterianos a $\mathrm{CuSO}_{4} \cdot 5 \mathrm{H}_{2} \mathrm{O}$ en medio líquido $\mathrm{LB}$ también se observó que transcurridas $48 \mathrm{~h}$ de incubación hubo crecimiento en todas las concentraciones evaluadas $\left(0,32,80\right.$ y $120 \mu \mathrm{g} \mathrm{mL}^{-1} \mathrm{de}$ 
$\mathrm{Cu}^{+2}$ ) y el mismo comportamiento para los aislados provenientes de Chillán, Negrete y Los Ángeles, y la mayor susceptibilidad al cobre en los aislados de Mulchén. La susceptibilidad observada en las cepas de Mulchén puede deberse a que al lado del lugar desde donde se obtuvieron los frutos enfermos se encuentra un predio de nogales abandonado, el cual puede ser un foco de infección hacia el predio muestreado, que por diseminación por el viento puede trasladar poblaciones de Xaj, que tienen nula presión de selección por cobre, manteniendo así la prevalencia de poblaciones susceptibles de la bacteria en este huerto.

En la determinación de la susceptibilidad de los aislados bacterianos a distintas sales de cobre (Tabla 1), transcurridas $48 \mathrm{~h}$ de incubación bacteriana, se obtuvo crecimiento bacteriano en las soluciones en base a óxido de cobre (I) $(1.500 \mu \mathrm{g}$ $\mathrm{mL}^{-1}$ de $\left.\mathrm{Cu}^{+2}\right)$ e hidróxido de cobre $\left(875 \mu \mathrm{g} \mathrm{mL}^{-1}\right.$ de $\mathrm{Cu}^{+2}$ ), en los aislados de las localidades de Los Ángeles, Negrete y Chillán, aunque un 50\% de los aislados de Chillán fueron reducidas con el óxido de cobre (I). Por su parte, el sulfato de cobre pentahidratado en una concentración de $1.180 \mu \mathrm{g}$ $\mathrm{mL}^{-1}$ de $\mathrm{Cu}^{+2}$ logró inhibir el crecimiento en todos los aislados evaluados.

Los resultados en el ensayo donde se igualaron las concentraciones de iones $\mathrm{Cu}^{+2}$ a $1.500 \mu \mathrm{g}$ $\mathrm{mL}^{-1}$ de $\mathrm{Cu}^{+2}$ de las diferentes sales de cobre utilizadas mostraron diferencias en el control ejercido entre los aislados obtenidos desde los distintos predios (Tabla 2), diferencias también reportadas en otros trabajos donde se evaluaron diferentes sales en base a cobre e igualaron las concentraciones de $\mathrm{Cu}^{+2}$ (Velázquez y Corroto, 2005; Roca et al., 2014).

Los resultados mostraron que existió inconsistencia en el control ejercido por el óxido de cobre (I), ya que en ambas experiencias se testeó a una misma concentración $\left(1.500 \mu \mathrm{g} \mathrm{mL}^{-1} \mathrm{de} \mathrm{Cu}^{+2}\right)$, pero, por ejemplo, los aislados de Chillán fueron controlados en su totalidad en este ensayo, mientras que en la primera experiencia sólo fueron controladas en un $50 \%$. La variabilidad observada para el óxido de cobre (I) en esta concentración sugiere que la solubilidad de la molécula puede ser variable e influiría en su eficacia sobre aislados resistentes. Por su parte, el hidróxido de cobre al incrementar su concentración de 875 a $1.500 \mu \mathrm{g} \mathrm{mL}^{-1}$ de $\mathrm{Cu}^{+2}$, aumentó considerablemente su eficiencia, llegando a controlar la totalidad de los aislados obtenidos en Chillán y Los Ángeles, y el 90\% de los aislados obtenidos de Negrete, las cuales habían mostrado crecimiento en la concentración menor. Los resultados y las diferencias en la susceptibilidad de los aislados a igual concentración de iones $\mathrm{Cu}^{+2}$ se explicarían por diferencias en la solubilidad de las diferentes sales evaluadas que influirían en la disponibilidad de estos iones en los medios para afectar a las bacterias y explicarían que bajo ciertas condiciones podría haber una mayor o menor liberación de estos iones dependiendo de la sal utilizada, siendo el hidróxido de cobre y el sulfato de cobre más solubles por ende favoreciendo el contenido de este ion en el medio líquido y siendo más efectivos a menores concentraciones. Por su parte, los aislados de Mulchén no crecieron en las distintas sales en base a cobre evaluadas, lo cual respalda la susceptibilidad innata que estos aislados presentaron al ion cobre. Estos resultados ponen en evidencia la importancia de la fuente de cobre a utilizar en el control de la peste negra debido a las diferencias mostradas en la efectividad de control, situación que de no considerarse podría incidir en la aparición de nuevas cepas resistentes al exponerlas a dosis subletales del elemento, tal como lo manifiestan Andersen et al. (1991).

Tabla 1. Porcentaje de sobrevivencia de aislados de Xanthomonas arboricola $\mathrm{pv}$. juglandis $(\mathrm{n}=10$ aislados por predio) obtenidos desde cuatro nocedales de distintas localidades de la Región del Biobío y crecidos en diferentes concentraciones de iones $\mathrm{Cu}^{+2}$ obtenido a partir de $\mathrm{CuSO}_{4}$ $x 5 \mathrm{H}_{2} \mathrm{O}$.

Table 1. Percentage of surviving strains of Xanthomonas arboricola pv. juglandis ( $\mathrm{n}=\mathbf{1 0}$ isolates per orchard) obtained from four walnut orchards in different locations in the Biobío Region, which were grown at different concentrations of $\mathrm{Cu}^{+2}$ ion obtained from $\mathrm{CuSO}_{4} \times 5 \mathrm{H}_{2} \mathrm{O}$.

\begin{tabular}{ccccr}
\hline \multirow{2}{*}{$\begin{array}{l}\text { Concentración } \\
\text { iones } \mathbf{C u}^{+2}\end{array}$} & \multicolumn{4}{c}{ Porcentaje de aislados sobrevivientes } \\
\cline { 2 - 5 }$\mu \mathrm{g} \mathrm{mL} \mathbf{~}^{-1}$ & Chillán & Los Ángeles & Negrete & Mulchén \\
\hline 0 & 100 & 100 & 100 & 100 \\
32 & 100 & 100 & 100 & 0 \\
80 & 100 & 100 & 100 & 10 \\
120 & 100 & 100 & 100 & 0 \\
\hline
\end{tabular}


Tabla 2. Porcentaje de sobrevivencia de aislados de Xanthomonas arboricola $\mathrm{pv}$. juglandis $(\mathrm{n}=\mathbf{1 0}$ aislados por huerto) obtenidos desde cuatro nocedales ubicados en cuatro localidades de la Región del Biobío y crecidos en diferentes sales y concentraciones de iones de cobre ( $\mu \mathrm{g}$ $\mathrm{mL}^{-1}$ de $\mathrm{Cu}^{+2}$ ).

Table 1. Percentage of surviving strains of Xanthomonas arboricola $\mathbf{p v}$. juglandis $(\mathrm{n}=\mathbf{1 0}$ isolates per orchard) obtained from four walnut orchards in different locations in the Biobío Region, which were grown at different copper compounds and concentrations of $\mathrm{Cu}^{+2}$ ion $\left(\mu \mathrm{gLL}^{-1}\right.$ de $\left(\mathbf{u}^{+2}\right)$.

\begin{tabular}{|c|c|c|c|c|c|c|c|}
\hline \multirow{4}{*}{$\begin{array}{l}\begin{array}{l}\text { Fuentes de } \\
\text { cobre testeadas }\end{array} \\
\text { Huerto }\end{array}$} & \multicolumn{7}{|c|}{ Porcentaje de aislados sobrevivientes } \\
\hline & Control & \multicolumn{2}{|c|}{$\begin{array}{l}\text { Hidróxido de } \\
\text { cobre }\end{array}$} & \multicolumn{2}{|c|}{ Óxido de cobre (I) } & \multicolumn{2}{|c|}{$\begin{array}{l}\text { Sulfato de cobre } \\
\text { pentahidratado }\end{array}$} \\
\hline & \multicolumn{7}{|c|}{$\mu g \mathrm{~mL}^{-1} \mathrm{de} \mathrm{Cu}^{+2}$} \\
\hline & 0 & 875 & 1.500 & 1.500 & 1.500 & 1.180 & 1.500 \\
\hline Chillán & 100 & 100 & 0 & 50 & 0 & 0 & 0 \\
\hline Los Ángeles & 100 & 100 & 0 & 100 & 100 & 0 & 0 \\
\hline Negrete & 100 & 100 & 10 & 100 & 90 & 0 & 0 \\
\hline Mulchén & 100 & 0 & 0 & 0 & 0 & 0 & 0 \\
\hline
\end{tabular}

\section{CONCLUSIONES}

Aislados de Xanthomonas arboricola pv. juglandis obtenidos desde tres nocedales de la región del Biobío mostraron un incremento en la resistencia al ion cobre con respecto a resultados reportados anteriormente en Chile, y en concentraciones por sobre $1.000 \mu \mathrm{g}$ de ión cobre por $\mathrm{mL}^{-1}$ distintas sales de cobre presentan variación en su eficacia para reducir estos aislados.

\section{LITERATURA CITADA}

Andersen, G, O. Menkissoglou, and S. Lindow. 1991. Occurrence and properties of copper-tolerant strains of Pseudomonas syringae isolated from fruit trees in California. Phytopathology 81(6):648-656.

Basim, H., G.V. Minsavage, R.E. Stall, J.-F. Wang, S. Shanker, and J.B. Jones. 2005. Characterization of a unique chromosomal copper resistance gene cluster from Xanthomonas campestris pv. vesicatoria. Appl. Environ. Microbiol. 71(12):8284-8291.

Behlau, F., B.I. Canteros, J.B. Jones, and J.H. Graham. 2012. Copper resistance genes from different xanthomonads and citrus epiphytic bacteria confer resistance to Xanthomonas citri subsp. citri. Eur. J. Plant Pathol. 133(4):949963.

Esterio, M., J. Auger, L. Agurto, e I. Pérez. 2006. Resistencia de Xanthomonas arboricola pv. juglandis al ion cobre en Chile. Fitopatología 41(3):93-101.
Gardan, L., T. Brault, and E. Germain. 1993. Copper resistance of Xanthomonas campestris pv. juglandis in French walnut orchards and its association with conjugative plasmids. Acta Hortic. (311):259-265.

Gómez-Marín, A.M., D. Naranjo-Fernández, O.I. Montoya, y D.J. Gallego. 2009. Efectos de algunos componentes del medio del cultivo en la producción de melanina bacteriana. BioTecnología 13(2):11-23.

Higueras G., N. González-Escalona, C. Véliz , F. Vera, y J. Romero. 2015. Draft genome sequences of four Xanthomonas arboricola pv. juglandis strains associated with walnut blight in Chile. Genome Announc. 3(5):e01160-15. doi:10.1128/genomeA.01160-15.

Jones, J.B., G.H. Lacy,., H. Bouzar, R.E. Stall, , and N.W. Schaad. 2004. Reclassification of the xanthomonads associated with bacterial spot disease of tomato and pepper. Syst. Appl. Microbiol. 27:755-762.

Lamichhanne, J.R. 2014. Xanthomonas arboricola Diseases of stone fruit, almond, and walnut trees: Progress toward understanding and management. Plant Dis. 98(12):1600-1610. http://dx.doi.org/10.1094/PDIS-08-14-0831FE

Lamichhane, J.R., and L. Varvaro. 2014. Xanthomonas arboricola disease of hazelnut: Current status and future perspectives for its management. Plant Pathol. 63:243-254.

Larrañaga, P., y M.A. Osores. 2012. Catastro frutícola: principales resultados. Región del Biobío. Julio 2012. ODEPA / CIREN, Santiago, Chile. 
Leach, J.E., C.M. Vera, J. Bai, and H. Leung. 2001. Pathogen fitness penalty as a predictor of durability of disease resistance genes. Annu. Rev. Phytopathol. 39:187-224.

Lee, Y.-A., M.N. Schroth, M. Hendson, S.E. Lindow, X.-L. Wang, B. Olson, et al. 1993. Increased toxicity of iron-amended copper-containing bactericides to the walnut blight pathogen Xanthomonas campestris pv. juglandis. Phytopathology 83(12):1460-1465.

Lee, Y.A., M. Hendson, N.J. Panopoulos, and M.N. Schroth. 1994. Molecular cloning, chromosomal mapping, and sequence analysis of copper resistance genes from Xanthomonas campestris pv. juglandis: homology with small blue copper proteins and multicopper oxidase. J. Bacteriol. 176(1):173.

Lindow, S., W. Olson, and R. Buckner. 2014. Colonization of dormant walnut buds by Xanthomonas arboricola pv. juglandis is predictive of subsequent disease. Phytopathology 104:1163-1174.

López-Cardona, N. y J. Castaño-Zapata. 2011. Evaluación in vitro de la eficacia de bactericidas sobre Pseudomonas sp. Migula, causante de la muerte descendente del tomate de árbol [Solanum betaceum (Cav.) Sendt.]. Agronomía (Manizales) 19(1):31-41.

Menkissoglu, O., and S.E. Lindow. 1991. Relationship of free ionic copper and toxicity to bacteria in solutions of organic compounds. Phytopathology 81(10):1258-1263.

Moragrega, C. 2001. Detached immature fruit inoculation method for evaluation of walnut resistance to Xanthomonas arboricola pv. juglandis [on line]. Cost 873, Switzerland. $<$ http://cost873.ch/_uploads/_files/Moragrega_WalnutImmatureFruitXajMethod.pdf $>$. [Acessed 24 octubre 2014].

Moragrega, C. 2012. Detection and identification methods and new tests as developed and used in the framework of Cost 873 for bacteria pathogenic to stone fruits and nuts: Xanthomonas arboricola pv. juglandis. J. Plant Pathol. 94(Suppl. 1):S1.155-S1.159.
Murillo, J. y P. Rodríguez-Palenzuela. 1996. Biología molecular de las interacciones entre plantas y bacterias fitopatógenas. p. 559-586. En G. Llácer, M.M. López, A. Trapero y A. Bello (eds.). Patología vegetal. Phytoma. Ediciones Mundi-Prensa. Sociedad Española de Fitopatología, Madrid, España.

Ninot, A., N. Aletà, C. Moragrega, and E. Montesinos. 2002. Evaluation of a reduced copper spraying program to control bacterial blight of walnut. Plant Dis. 86(6):583-587.

Pérez, I.E. 2005. Determinación de la variabilidad genética de cepas de Xanthomonas arboricola pv. juglandis, utilizando la técnica de reacción en cadena de la polimerasa (PCR). Tesis Ingeniero Agrónomo. Universidad de Chile, Facultad de Ciencias Agronómicas, Escuela de Agronomía, Santiago, Chile.

Ramos, G., and Y.B. Rosato. 1996. Copper accumulation in Xanthomonas campestris pv. vesicatoria. Braz. J. Genet. 19(4):551-554.

Roca, L.F., P. Miranda de Fuentes, y A. Trapero. 2014. Eficacia de los productos cúpricos en el control de la tuberculosis del olivo. Vida Ru$\operatorname{ral}(385): 48-52$.

Temperini, C.V., A.G. Pardo, y G.N. Pose. 2014. Bacteriosis y necrosis apical del nogal: Complejos microbianos involucrados en la caída temprana de frutos en el Valle Medio del Río Negro. Revista SENASA (5-6):9-14.

Vauterin, L., B. Hoste, K. Kersters, and J. Swings. 1995. Reclassification of Xanthomonas. Int. J. System. Bacteriol. 45(3):472-489.

Velázquez, P., y A.J.M. Corroto. 2005. Evaluación de bactericidas cúpricos para el control de cancrosis en plantines de pomelo. En V Congreso argentino de citricultura. Del 30 de noviembre al 02 de diciembre, 2005. INTA. Estación Experimental Agropecuaria Concordia, Entre Ríos, Argentina. 